\title{
Irradiation tests of bolometer sensor prototypes for ITER
}

\author{
H. Meister ${ }^{\mathrm{a}}$, S. Schmitt ${ }^{\mathrm{b}}$, I. Szenthe ${ }^{\mathrm{c}}$, A. Szakál ${ }^{\mathrm{c}}$, H. Albrecht ${ }^{\mathrm{d}}$, F. Gillemot ${ }^{\mathrm{c}}$ \\ ${ }^{a}$ Max-Planck-Institut für Plasmaphysik, Boltzmannstr. 2 D-85748 Garching, Germany \\ ${ }^{b}$ Fraunhofer-IMM, Carl-Zeiss-Str. 18-20, D-55129 Mainz, Germany \\ ${ }^{c}$ Centre for Energy Research, Hungarian Academy of Sciences, Konkoly-Thege Miklós 29-33, H-1121 Budapest, Hungary \\ ${ }^{d} I P T-A l b r e c h t$ GmbH, Waldweg 37, D-77963 Schwanau, Germany
}

\begin{abstract}
In ITER, the bolometer diagnostic is foreseen to provide the measurements for the total plasma radiation. Sensors need to withstand the harsh environmental conditions. Most prominent among those is the nuclear environment with neutron fluxes up to $10^{13} \mathrm{n} / \mathrm{cm}^{2} \mathrm{~s}$ at the locations of bolometers, which result in a radiation dose of up to $0.3 \mathrm{dpa}$ in $\mathrm{Si}_{3} \mathrm{~N}_{4}$. Original metal resistor bolometer sensors based on Au-absorbers on a mica substrate with Au-meanders failed when exposed to fast neutron fluences corresponding to $0.1 \mathrm{dpa}$. Various material tests under irradiation identified ceramic materials like $\mathrm{Al}_{2} \mathrm{O}_{3}$, AlN or $\mathrm{Si}_{3} \mathrm{~N}_{4}$ together with Pt meanders as promising alternatives. Based on these ideas a development campaign was initiated to produce a radiation hard bolometer sensor. Two approaches resulted in good mechanical stability under thermal cycling: Au absorbers supported by a $\mathrm{Si}_{3} \mathrm{~N}_{4}$ membrane and $\mathrm{Au}$ absorbers on a silicon base plate which is hung up by flexure hinges. In order to assess their resistance against irradiation, tests have been conducted in the Budapest Neutron Centre. The test campaign demonstrated for the first time that bolometer sensors can withstand irradiation doses corresponding up to 0.3 dpa in $\mathrm{Si}_{3} \mathrm{~N}_{4}$, which is higher than the value of 0.1 dpa requested by ITER project requirements, while their meander resistance measured after irradiation increased only by $20-30 \Omega$.
\end{abstract}

Keywords: ITER, bolometer, irradiation, plasma diagnostics

\section{Introduction}

In fusion experiments the total plasma radiation makes up one part of the energy balance of the plasma. To measure the plasma radiation integrated over a wide spectral range bolometers are used in most cases. Also in ITER, the bolometer diagnostic is foreseen to provide these measurements. When developing this diagnostic for ITER based on experience from current experimental devices, one has to consider the harsh environmental conditions which impose significantly more stringent requirements on sensor and components [1]. Most prominent among those is the nuclear environment with neutron fluxes up to $10^{13} \mathrm{n} / \mathrm{cm}^{2} \mathrm{~s}$ at the locations of bolometers produced by the deutrium-tritium (D-T) reactions, which result in a radiation dose of up to $0.3 \mathrm{dpa}$ in $\mathrm{Si}_{3} \mathrm{~N}_{4}$ [2]. Original metal resistor bolometer sensors based on Au-absorbers on a mica substrate with Au-meanders [3], which have also been used during the D-T campaign in JET in 1997, showed a reduced life-time when exposed to fast neutron fluences corresponding to $0.1 \mathrm{dpa}$ [4]. Various material tests un- der irradiation identified ceramic materials like $\mathrm{Al}_{2} \mathrm{O}_{3}$, $\mathrm{AlN}$ or $\mathrm{Si}_{3} \mathrm{~N}_{4}$ together with $\mathrm{Pt}$ meanders as promising alternatives [5-8]. Based on these ideas a development campaign was initiated to produce a bolometer sensor based on Pt absorbers on $\mathrm{Si}_{3} \mathrm{~N}_{4}$ membranes with Pt meanders. Initial tests showed a good sensitivity $[9,10]$ but mechanical stability at high temperatures [11] and under irradiation [12] proved to be insufficient. To improve mechanical stability at high operating temperatures two approaches have been followed: supporting the absorber using flexure hinges [13] and using absorbers made of Au instead of Pt [14]. Both approaches resulted in good thermal stability. In order to assess their resistance against irradiation, tests have been conducted in the Budapest Research Reactor (BRR), which is part of the Budapest Neutron Centre. This paper describes the samples tested, the set-up in the reactor, irradiation conditions and the post irradiation examination results. 


\section{Set-up of irradiation test}

\subsection{Bolometer sensor samples}

Two types of sensors have been irradiated, $\mathrm{Au}$ absorbers supported by $\mathrm{Si}_{3} \mathrm{~N}_{4}$ membranes [14] and absorbers supported by a thin $\mathrm{Si}$ plate connected to the Si-frame with flexure hinges [13]. Figure 1 shows schematically the materials and layers on top and a foto of half of an absorber with connecting tracks below. For the $\mathrm{Au}$ absorbers supported by a $\mathrm{Si}_{3} \mathrm{~N}_{4}$ membrane (left column), one can identify the edge of the absorber by the yellow border, the meander with the track connections from top and the membrane by the medium grey area around the absorber. For the absorber supported by a Si disc and flexure hinges (right column) one can identify the hinges which support the disc with absorber hanging freely as indicated by the white area corresponding to the background on which the sensor was placed for taking the foto. The absorber itself cannot be seen. The connection to the meander is in this case on the top left and right corner of the Si disc along the two hinges with the lighter color. The other two darker hinges are not covered by the Pt layer of the tracks.

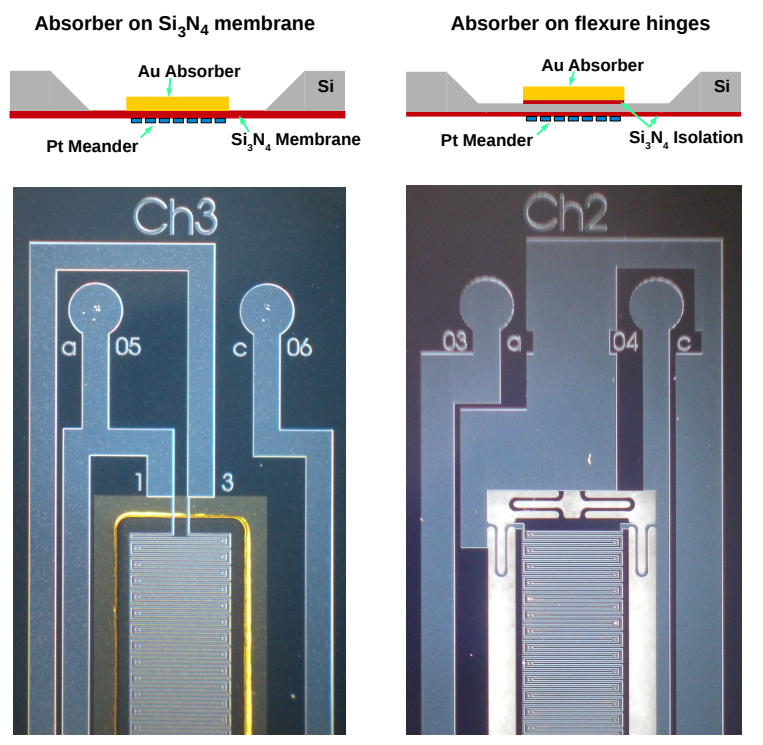

Figure 1: Sketch of the materials and layers of the bolometer sensor types (top) and foto of half of an absorber with connecting tracks (bottom).

For both types the samples had been mounted into sensor holders to protect them from mechanical damage. A sketch of the sensor holder is shown in Figure 2. The sensor was placed in a depression of the back plate and covered by the front plate to keep it in place. Front and back plate were made of Shapal-M, a sintered

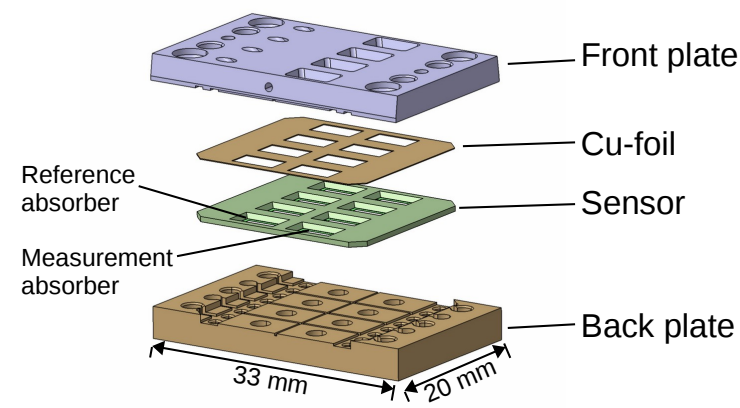

Figure 2: Sketch of the bolometer sensor holder for a four channel sensor.

AlN/BN ceramic. Two M2x5 steel screws were used to fix the assembly. If needed, four stripes of individual channels can be used instead of the four channel sensor as shown in Figure 2. To protect the sensor against mechanical influences, a $0.1 \mathrm{~mm}$ thin foil made of pure soft $\mathrm{Cu}$ was used in between sensor and front plate.

The four channel sensor with absorbers supported by flexure hinges ${ }^{1}$ had been mounted in the holder labeled \#12 (Figure 3, left column). The sensor holder labeled \#13 contained four different individual sensor channels (Figure 3, right column): left and middle-left sensors (corresponding to channels 4 and 3, respectively) had a $20 \mu \mathrm{m} \mathrm{Au-absorber} \mathrm{with} \mathrm{an} \mathrm{adhesion} \mathrm{layer} \mathrm{of} 15 \mathrm{~nm}$ $\mathrm{CrO}$ and $300 \mathrm{~nm} \mathrm{Pt} \mathrm{each}{ }^{2}$; in the middle-right (corresponding to channel 2) was a sensor with a $5 \mu \mathrm{m} \mathrm{Au}-$ absorber, an adhesion layer of $100 \mathrm{~nm} \mathrm{Ti}$ and $100 \mathrm{~nm}$ $\mathrm{Ag}$ and covered first by a $150 \mathrm{~nm}$ Al-layer to reduce the cooling time constant and an additional layer of $50 \mathrm{~nm}$ sputtered $\mathrm{C}$ to enhance the absorption in the VIS and VUV spectral range $^{3}$; the right sensor (corresponding to channel 1) was identical to the middle-right one except for the missing C-layer ${ }^{4}$. These combinations are summarized in Table 1.

After assembling the sensors into the holders the resistances of the samples had been measured using spring loaded contact pins and a dedicated set-up for testing bolometer sensors in the lab (see as example Figure 6). The resistance for all six combinations of contacting the four contacts per bolometer channel had been measured (see Table 3). The numbering of the contact pins are defined in Figure A.10.

Using the approximation described in Appendix A,

\footnotetext{
${ }^{1}$ chip H from wafer 2315, flowchart 1600033

${ }^{2}$ sensors D2 and D1 of wafer 4551, flowchart 1800038

${ }^{3}$ sensor P1, wafer 2046, flowchart 1600032

${ }^{4}$ sensor O1, wafer 2046, flowchart 1600032
} 
Table 1: Summary of sensor types used for irradiation.

\begin{tabular}{|c|c|c|c|c|c|}
\hline Holder & $\# 12$ & \multicolumn{4}{|c|}{$\# 13$} \\
\hline Channel & $1-4$ & $\mathbf{1}$ & 2 & 3 & 4 \\
\hline Support & $\begin{array}{l}50 \mu \mathrm{m} \text { Si disc and } \\
\text { flexure hinges }\end{array}$ & $3 \mu \mathrm{m} \mathrm{Si}_{3} \mathrm{~N}_{4}$ & $3 \mu \mathrm{m} \mathrm{Si}_{3} \mathrm{~N}_{4}$ & $3 \mu \mathrm{m} \mathrm{Si}_{3} \mathrm{~N}_{4}$ & $3 \mu \mathrm{m} \mathrm{Si}_{3} \mathrm{~N}_{4}$ \\
\hline Absorber & $20 \mu \mathrm{m} \mathrm{Au}$ & $5 \mu \mathrm{m} \mathrm{Au}$ & $5 \mu \mathrm{m} \mathrm{Au}$ & $20 \mu \mathrm{m} \mathrm{Au}$ & $20 \mu \mathrm{m} \mathrm{Au}$ \\
\hline Adhesion layer & & $\begin{array}{l}100 \mathrm{~nm} \mathrm{Ti}^{+} \\
100 \mathrm{~nm} \mathrm{Ag}\end{array}$ & $\begin{array}{l}100 \mathrm{~nm} \mathrm{Ti} \\
100 \mathrm{~nm} \mathrm{Ag}\end{array}$ & $\begin{array}{l}15 \mathrm{~nm} \quad \mathrm{Cr}+ \\
300 \mathrm{~nm} \mathrm{Pt}\end{array}$ & $\begin{array}{l}15 \mathrm{~nm} \quad \mathrm{Cr} \\
300 \mathrm{~nm} \mathrm{Pt}\end{array}$ \\
\hline Coating & none & $150 \mathrm{~nm} \mathrm{Al}$ & $\begin{array}{ll}150 \mathrm{~nm} & \mathrm{Al} \\
50 \mathrm{~nm} \mathrm{C} & \end{array}$ & none & none \\
\hline
\end{tabular}
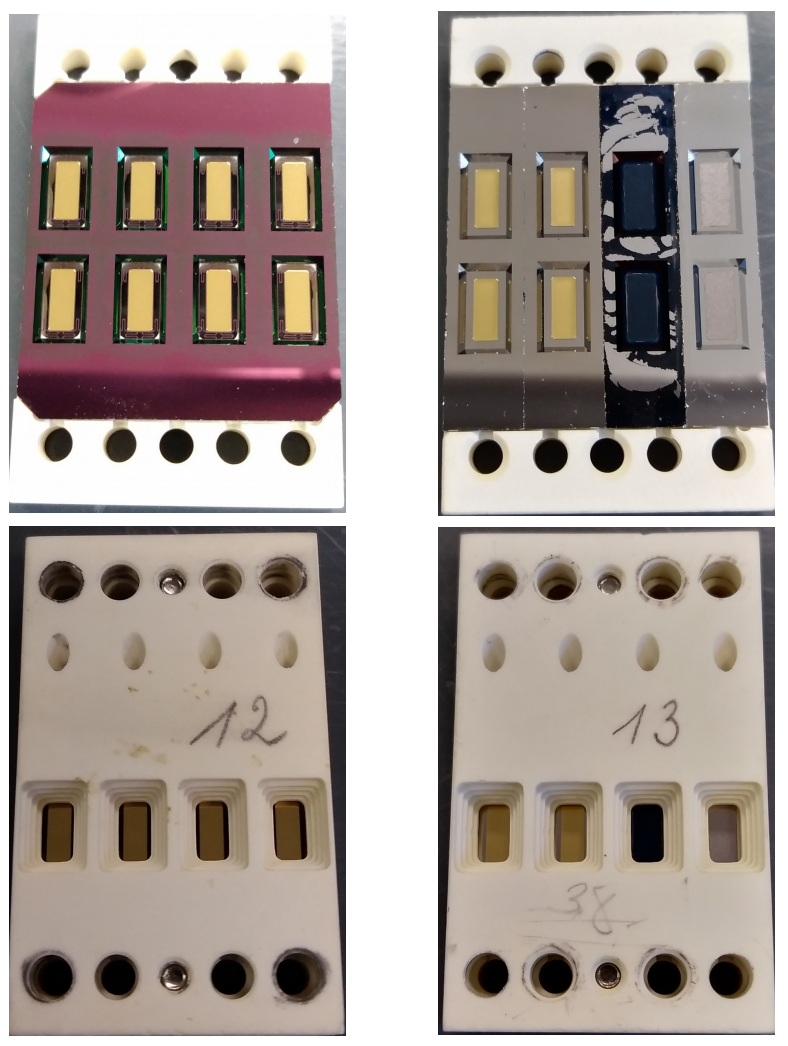

Figure 3: Sensor samples used for irradiation: 4-channel sensor with absorbers supported by flexure hinges in holder labeled \#12 (left) and 4 individual sensor channels of various types as described in the text in sensor holder labeled \#13 (right). Upper row without front plate, lower row with front plate.

the resistances of the individual meanders can be calculated. The results of these measurements are given in Table 4.

\subsection{Irradiation rig}

A custom assembly has been built to insert the sensor holders into a standard irradiation capsule as shown in Figure 4. The left part shows on top the standard irradiation capsule made of aluminium and on the lower the two sensor holders placed between the custom built

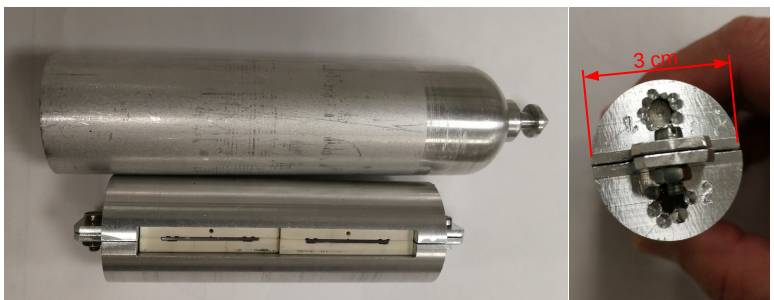

Figure 4: Irradiation rig: side view (left) and front view (right) of the custom made holders to tightly fit the sensor assemblies into the capsule (upper part on left side).

halves made of aluminium alloy $\left(\mathrm{AlMgSi}_{3}\right)$ to perfectly fit them into the centre of the capsule and support the heat removal by good thermal contact to the surroundings. The right part of Figure 4 shows the front view of the custom assembly. The upper half (labeled 1) contains a temperature monitor made of $\mathrm{Pb}_{10} \mathrm{In}$ (melting temperature $291^{\circ} \mathrm{C}$ ), the lower one (labeled 2) contains a melting temperature monitor made out of $\mathrm{Pb}_{5} \mathrm{Ag}_{5} \mathrm{Sn}$ (melting temperature $292^{\circ} \mathrm{C}$ ). These temperature monitors were included as the samples irradiated have proven in previous testing (e.g. [13]) that they can withstand thermal cycling at least up to $291{ }^{\circ} \mathrm{C}$ and thus a method was given to decide if a temperature spike during irradiation might have led to failures or not.

During assembly all parts were cleaned with denaturated alcohol. The assembled capsule was closed hermetically by metal spinning, but not evacuated; the sensors were surrounded by air.

\subsection{Irradiation conditions}

The capsule was inserted in a fast irradiation channel (no. 426) for two irradiation cycles of about 10 days each (439 hours of irradiation in total). The neutron spectrum shown in Figure 5 was calculated in 60 energy groups using the detailed MCNPX model of the reactor. This results in the neutron fluxes within the irradiation channel as given in table 2 and accumulated to a total fast fluence of $9 \cdot 10^{19} \mathrm{n} / \mathrm{cm}^{2}$. 


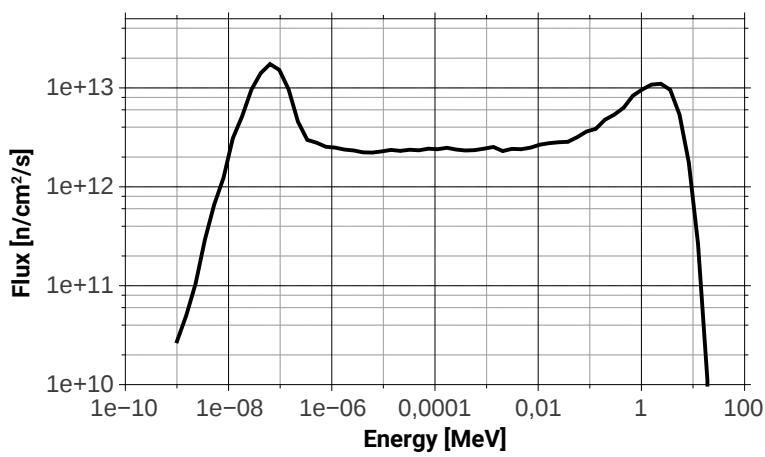

Figure 5: Neutron spectrum of BRR reactor.

\begin{tabular}{|l|c|}
\hline total flux & $2.37 \cdot 10^{14} \frac{\mathrm{n}}{\mathrm{cm}^{2} \cdot \mathrm{s}}$ \\
\hline thermal flux $(E<250 \mathrm{meV})$ & $8.1 \cdot 10^{13} \frac{\mathrm{n}}{\mathrm{cm}^{2} \cdot \mathrm{s}}$ \\
\hline epithermal flux $(250 \mathrm{meV}<E<0.5 \mathrm{MeV})$ & $9.9 \cdot 10^{13} \frac{\mathrm{n}}{\mathrm{cm}^{2} \cdot \mathrm{s}}$ \\
\hline fast neutron flux $(E>0.5 \mathrm{MeV})$ & $5.7 \cdot 10^{13} \frac{\mathrm{n}}{\mathrm{cm}^{2} \cdot \mathrm{s}}$ \\
\hline
\end{tabular}

Table 2: Total neutron fluxes during irradiation.

The temperature of the samples during the irradiation was not controlled actively. However, due to the very good thermal contact within the capsule and to the surrounding cooling water, the temperature could be estimated to $70 \pm 5^{\circ} \mathrm{C}$ based on the total reactor power (constant at $10 \pm 0.15 \mathrm{MW}$ ) and the thermal balance given by gamma heating, heating-cooling processes, and approximately constant flux followed the fuel burning, which was measured at the start and the end of the cycle. The temperature monitors included in the assembly confirmed that during the whole irradiation cycle the temperature never exceeded the limit of $291^{\circ} \mathrm{C}$.

These irradiation conditions have been used to determine the resulting dose rate in $\mathrm{Si}_{3} \mathrm{~N}_{4}$ in terms of displacements per atom according to the method described in [15], using a displacement efficiency of 0.8 and a displacement energy of $40 \mathrm{eV}$ [16] together with the ENDF/B-VII.1 cross-section library. The calculated dose rate of $2.0 \cdot 10^{-7} \mathrm{dpa} / \mathrm{s}$ results thus in an accumulated dose of $0.3 \mathrm{dpa}$ in $\mathrm{Si}_{3} \mathrm{~N}_{4}$ for the total irradiation time. Its accuracy is estimated to about $6 \%$ based on the statistical errors and a conservative assumption of the systematic uncertainties of the spectrum calculation. The former are in the order of 3\%, the latter about $5 \%$ (the MCNP model describes the reactor properties in general very well) and Gaussian weighting has been applied.

\section{Post-irradiation examination and discussion of results}

The post irradiation examination (PIE) was carried out in two steps. On the first try, after 7 weeks of cooldown, the activity at the surface of the samples was still in the order of $2 \mathrm{mSv} / \mathrm{h}$. Accordingly, samples could be handled only using tongs and behind a lead window to shield against radiation. Visual inspection from slightly more than half a meter distance revealed no obvious defects. However, despite the set-up to connect the sensor inside its holder using spring loaded contacts (as in Figure 6), but without bolts to secure it. Due to the activation level only tongs with long handles could be used to press the holder against the spring loaded contacts. No reliable electrical connection could be established as the sensor holder could not be pressed evenly against the pins using the tongs. During further handling one of the membranes supporting the absorbers of channel 4 from holder \#13 broke.

After further cool-down for another 7 months the activity of the samples reduced to $300 \mu \mathrm{Sv} / \mathrm{h}$ at the surface and a second PIE was scheduled. The reduced activity allowed for easier handling. Again, visual inspection from a short distance showed no additional damage. The sensor holders were placed on the measurement set-up (see Figure 6), secured with bolts and resistance measurements were tried. The result showed

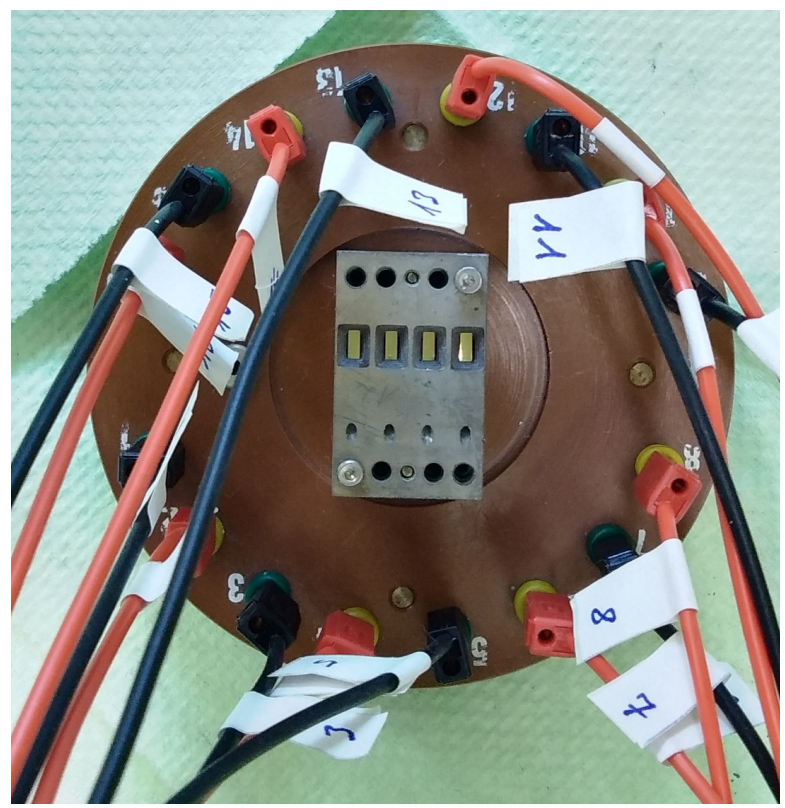

Figure 6: Sensor holder \#12 placed in electrical measurement set-up for PIE.

that no reliable electrical contact could be established; 
resistances were all exceeding the $\mathrm{M} \Omega$-range.

A disassembly of the sensor holders resulted in breaking a membrane of channel 3 of holder \#13 due to not careful enough handling. Visual inspection as shown in Figure 7 reveals the broken membranes as well as the reason for unsuccessful electrical measurements: the electrical contact pads on the sensors were destroyed. Obviously, remote handling of the active samples during the first PIE resulted in the spring loaded contacts having scratched away the contact pads on the sensors. A close-up view of parts of the not broken channels us-

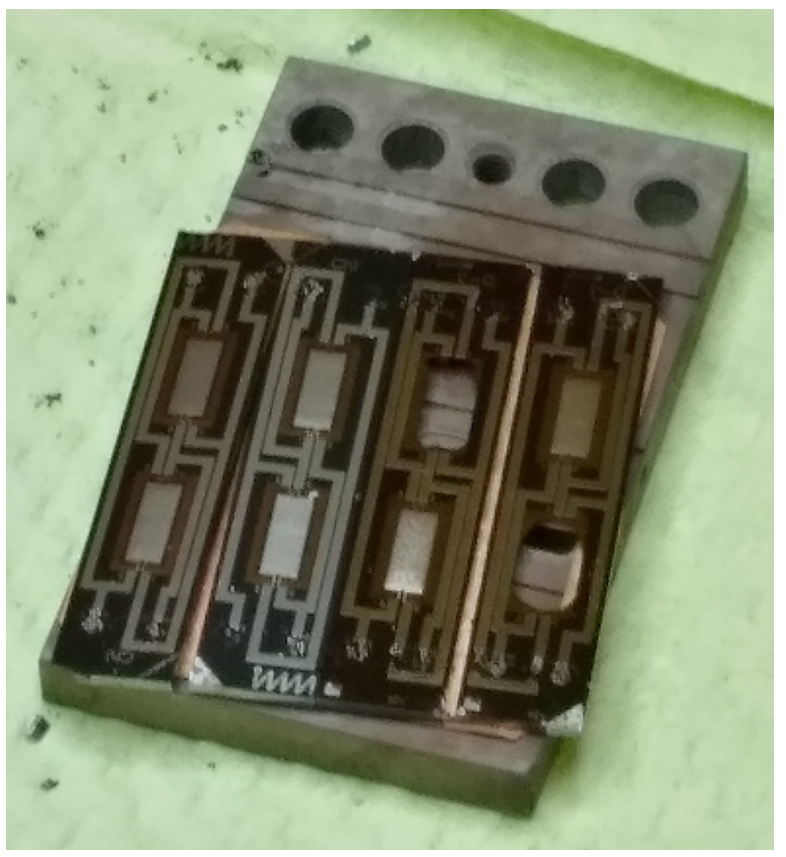

Figure 7: Post-irradiation visual inspection of disassembled bolometer sensors from holder \#13.

ing a microscope is given in Figure 8. The contact pads of holder \#12 are scratched away completely, those of holder \#13 partially. Tracks and meanders seem not to be affected, apart from the debris due to scratching they show a smooth picture. The flexure hinges holding the absorbers in holder \#12 are clearly distinguishable and no breaks are visible in the membranes supporting the absorbers in holder \#13 (dark area around meanders). This visual inspection demonstrates that apart from the scratches due to handling no obvious damage occurred to the samples. Irrespective of the composition of the sensors, neither tracks nor absorbers indicate de-lamination from the substrate. The sensors remained intact during the whole irradiation cycles.

Having the indication that sensors should still be functioning, individual channels were contacted close

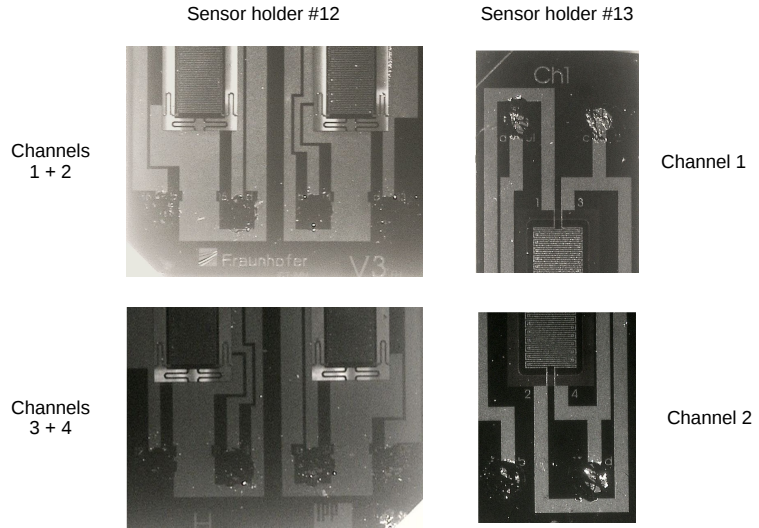

Figure 8: Post-irradiation inspection of contact pads for sensor holders \#12 and \#13. The contact pads of holder \#12 are scratched away completely, those of holder \#13 partially. Tracks and meanders seem not to be affected.

to the original contact pads on the electrical tracks using thin measurement pins. Electrical connections could thus indeed be established and resistances measured. However, not all six contacts per channel could be established for every sample. The reasons were on the one hand the fragile contacting procedure conducted manually under the microscope and on the other hand that the limits in time while handling irradiated samples had to be observed. Successful measurements have been obtained for channel 1 of each sensor holder. The results are given in Table 3 together with those acquired before irradiation. For the other channels, resistance mea-

Table 3: Measured resistances for the samples investigated before and after irradiation. Values are given in $\Omega$. Naming of pin contacts is given in Appendix A.

\begin{tabular}{|c|c|c|c|c|}
\hline \multirow{2}{*}{$\begin{array}{l}\text { Pin } \\
\text { contacts }\end{array}$} & \multicolumn{2}{|c|}{ Holder \#12 } & \multicolumn{2}{c|}{ Holder \#13 } \\
\cline { 2 - 5 } & $\begin{array}{l}\text { Before } \\
\text { irradia- } \\
\text { tion }\end{array}$ & $\begin{array}{l}\text { After } \\
\text { irradia- } \\
\text { tion }\end{array}$ & $\begin{array}{l}\text { Before } \\
\text { irradia- } \\
\text { tion }\end{array}$ & $\begin{array}{l}\text { After } \\
\text { irradia- } \\
\text { tion }\end{array}$ \\
\hline $1-16\left(R_{a b}\right)$ & 782 & 811 & 740 & 765 \\
\hline $16-2\left(R_{b c}\right)$ & 773 & 788 & 745 & 765 \\
\hline $2-15\left(R_{c d}\right)$ & 769 & 786 & 748 & 772 \\
\hline $1-15\left(R_{d a}\right)$ & 774 & 757 & 740 & 764 \\
\hline $1-2\left(R_{a c}\right)$ & 1030 & 1065 & 988 & 1023 \\
\hline $15-16\left(R_{b d}\right)$ & 1023 & 1047 & 989 & 1022 \\
\hline
\end{tabular}

surements of at least one diagonal of the measurement bridge ( $R_{a c}$ or $R_{b d}$ ) have been performed successfully to confirm their principal functionality.

Each contact attempt resulted in scratches on the electrical tracks. This resulted in increased uncertainties of the measured values and reduced the comparability to values measured before irradiation due to varying contact resistances. It is also obvious, that the scratches 
for the sample in holder \#12 are more pronounced than those for the samples in holder \#13. The reason is that the electrical tracks for the samples in holder \#13 are thicker $(750 \mathrm{~nm} \mathrm{Pt}$ compared to $250 \mathrm{~nm} \mathrm{Pt}$ ) and thus mechanically more resistant. It has to be noted that the tracks making up the meanders are in both cases $250 \mathrm{~nm}$ thick $\mathrm{Pt}$, thus resulting in similar values for the total resistance between contact pads, but slightly lower ones for those from sensor holder \#13.

Using the approximation described in Appendix A, the measured resistance values have been converted into resistance values for individual meanders. The summary of the thus derived values is given in table 4, together with the initial values before irradiation.

Table 4: Calculated resistance values for individual meanders of the samples before and after irradiation using measured values from Table 3 and the approximations described in Appendix A. Values are given in $\Omega$.

\begin{tabular}{|c|c|c|c|c|}
\hline \multirow{2}{*}{$\begin{array}{c}\text { Ch 1 } \\
R\end{array}$} & \multicolumn{2}{|c|}{ Holder \#12 } & \multicolumn{2}{c|}{ Holder \#13 } \\
\cline { 2 - 5 } & $\begin{array}{l}\text { Before } \\
\text { irradia- } \\
\text { tion }\end{array}$ & $\begin{array}{l}\text { After } \\
\text { irradia- } \\
\text { tion }\end{array}$ & $\begin{array}{l}\text { Before } \\
\text { irradia- } \\
\text { tion }\end{array}$ & $\begin{array}{l}\text { After } \\
\text { irradia- } \\
\text { tion }\end{array}$ \\
\hline$R_{m}$ & 1030 & 1051 & 990 & 1022 \\
\hline$R_{1}$ & 1045 & 1102 & 983 & 1019 \\
\hline$R_{2}$ & 1027 & 1056 & 993 & 1019 \\
\hline$R_{3}$ & 1019 & 1052 & 999 & 1033 \\
\hline$R_{4}$ & 1029 & 994 & 983 & 1017 \\
\hline
\end{tabular}

Comparing the calculated resistances before and after irradiation in Table 4 shows that in all cases they are slightly higher after irradiation. The increase in $R_{m}$ is $21 \Omega$ and $32 \Omega$. A similar increase has been observed already previously for similar samples [8]. Given the fact that both, meander resistances and irradiation doses, are about a factor of three higher for the current experiments, the increase of $20-30 \Omega$ is in line with the previously observed increase of $7.5 \Omega$. Comparing the resistances of $R_{1}, \ldots, R_{4}$ or the individual measurements from Table $3\left(R_{a b}, \ldots, R_{d a}\right)$ shows that variations of values after irradiation are more pronounced than before irradiation. Cross-checks in the lab with similar set-up and contacting methods demonstrated that using measurement pins typically results in an increased contact resistance of $2 \Omega$. Thus, the increased uncertainty is partially a result of the contacting method somewhere on the electrical tracks (but not on a clearly defined contact pad) as described above and may partially be due to the irradiation damage. The measurements do not allow to distinguish the effects.

Channel 2 in holder \#13 had a sensor coated with C on the absorber side, clearly visible in Figure 3, top right. After irradiation, this C-coating was removed from the absorber. As seen in Figure 9, there are still some patches of the black coating visible on the Siframe, but the absorber itself is blank and shiny. It

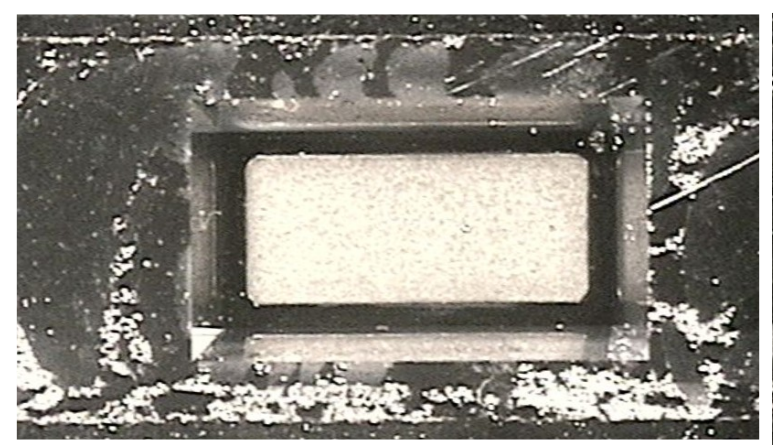

Figure 9: Post-irradiation inspection of C-coated absorber (holder $\# 13$, channel 2). Remnants of the black C-coating are visible only on the Si-frame, the absorber is blank and shiny.

is assumed that the reason is, that the inside of the irradiation capsule was not evacuated before irradiation. Accordingly, irradiation resulted in an ionizing environment producing $\mathrm{O}_{3}$ from the air in the capsule which removed the $\mathrm{C}$ by chemical erosion.

\section{Conclusions}

For the first time two kinds of fully functional bolometer sensor prototypes, one with absorbers supported by flexure hinges, one with $\mathrm{Au}$ absorbers supported by a $\mathrm{Si}_{3} \mathrm{~N}_{4}$ membrane and both with $\mathrm{Pt}$ meanders, have been irradiation tested up to dose rates of $0.3 \mathrm{dpa}$ in $\mathrm{Si}_{3} \mathrm{~N}_{4}$. The resistance measurements showed that the mean resistance measured after irradiation is higher by about $20-30 \Omega$ compared to before irradiation. This value which is fully compatible to bolometer operation. Breaking of individual channels occurred due to not careful enough handling during postirradiation examination, not due to the irradiation itself. No delamination of tracks or absorbers has been observed. Difficulties in measuring the resistances in PIE were encountered due to the manual contacting method directly on the sensor, which also resulted in enhanced uncertainty of the measurement values. So far, only the carbon coating used on one sensor channel was destroyed during irradiation. The assumption is that this is due to not having evacuated the irradiation capsule before exposure which could have promoted chemical erosion.

In view of fully validating bolometer sensors for ITER it is recommended to conduct one further irradiation campaign. On the one hand, various types of coating to enhance plasma radiation absorption in the 
VIS and VUV should be tested. To avoid erosion, samples should be tested inside an evacuated capsule. On the other hand, electrical contacts using wire bonding are recommended combined with an online measurement of the resistance. This will improve the reliability of the measurements and additionally provide the possibility to investigate if resistance increase is a linear function of the dose rate or exhibits a threshold behavior as well as performing sensor calibrations which would fully demonstrate the operation as a bolometer sensor.

\section{Acknowledgments}

The authors gratefully acknowledge the professional support of the reactor operating team during PIE!

\section{Appendix A. Measurement of resistances in a Wheatstone-bridge}

The metallic resistors in a bolometer channel, which are used to derive the measurement signal, are connected in the electrical scheme of a Wheatstone-bridge. For an ideal sensor all four resistors should be equal. As manufacturing tolerances always result in variations it is of importance to determine the individual values of the resistors.

A typical layout of the electrical tracks of a four channel bolometer sensor as seen when looking onto the meander side is given in Figure A.10. Measuring the re-

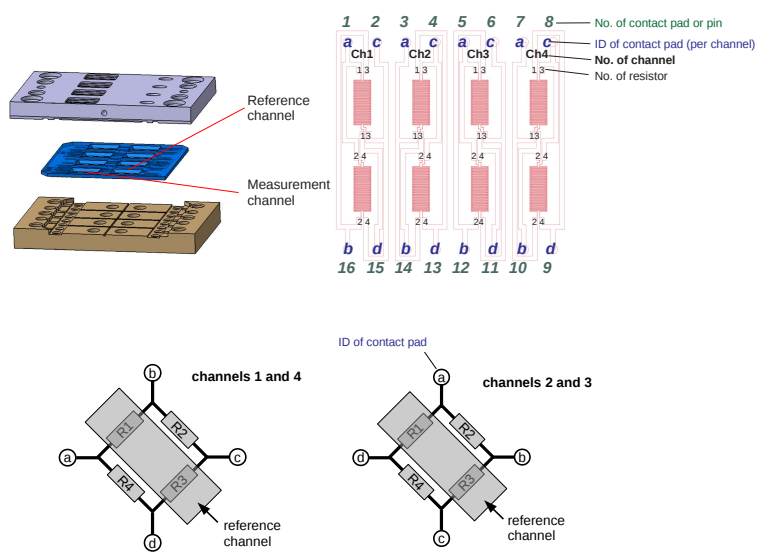

Figure A.10: Typical layout of electrical tracks of a four channel bolometer sensor (view onto the meander side) and the nomenclature used.

sistance by connecting for example to the contact pads $a$ and $d$ of channel 2, one would not measure only the resistance of $R_{1}$, but also the resistance of $R_{2}+R_{3}+R_{4}$ in parallel. Applying this to all four resistors for channel 2, one gets the following system of equations:

$$
\begin{aligned}
R_{a d} & =\left(\frac{1}{R_{1}}+\frac{1}{R_{2}+R_{3}+R_{4}}\right)^{-1} \\
& \left.=\frac{R_{1} \cdot\left(R_{2}+R_{3}+R_{4}\right)}{\sum R}\right)^{-1} \\
R_{a b} & =\left(\frac{1}{R_{2}}+\frac{1}{R_{1}+R_{3}+R_{4}}\right)^{-1} \\
& \left.=\frac{R_{2} \cdot\left(R_{1}+R_{3}+R_{4}\right)}{\sum R}\right)^{-1} \\
R_{b c} & =\left(\frac{1}{R_{3}}+\frac{1}{R_{1}+R_{2}+R_{4}}\right. \\
& =\frac{R_{3} \cdot\left(R_{1}+R_{2}+R_{4}\right)}{\sum R} \\
R_{c d} & =\left(\frac{1}{R_{4}}+\frac{1}{R_{1}+R_{2}+R_{3}}\right)^{-1} \\
& =\frac{R_{4} \cdot\left(R_{1}+R_{2}+R_{3}\right)}{\sum R}
\end{aligned}
$$

with $\sum R=R_{1}+R_{2}+R_{3}+R_{4}$. This system of equations cannot be solved directly as the individual $R_{i}$ to be determined appear in both, numerator and denominator. However, using the fact that manufacturing tolerances result in meander resistances which deviate less than $5 \%$ (typically less than $2 \%$ ) from a mean value $\bar{R}$, one can rewrite the definition of the $R_{i}$ according to

$$
\begin{array}{ll}
R_{1}=\bar{R}+\Delta R_{1} & R_{2}=\bar{R}+\Delta R_{2} \\
R_{3}=\bar{R}+\Delta R_{3} & R_{4}=\bar{R}+\Delta R_{4}
\end{array}
$$

The mean value of the resistances can be measured in a simple way by contacting the diagonal of the Wheatstone-bridge, for which the following two equations are valid:

$$
\begin{aligned}
R_{d b} & =\left(\frac{1}{R_{1}+R_{2}}+\frac{1}{R_{3}+R_{4}}\right)^{-1} \\
& =\frac{\left(R_{1}+R_{2}\right) \cdot\left(R_{3}+R_{4}\right)}{\sum R} \\
R_{a c} & =\left(\frac{1}{R_{1}+R_{4}}+\frac{1}{R_{2}+R_{3}}\right)^{-1} \\
& =\frac{\left(R_{1}+R_{4}\right) \cdot\left(R_{2}+R_{3}\right)}{\sum R}
\end{aligned}
$$


Using equations A.2 to rewrite equations A.1 one gets:

$$
\begin{aligned}
& R_{a d}=\frac{\left(\bar{R}+\Delta R_{1}\right) \cdot\left(3 \bar{R}+\Delta R_{2}+\Delta R_{3}+\Delta R_{4}\right)}{\sum R} \\
& R_{a b}=\frac{\left(\bar{R}+\Delta R_{2}\right) \cdot\left(3 \bar{R}+\Delta R_{1}+\Delta R_{3}+\Delta R_{4}\right)}{\sum R} \\
& R_{b c}=\frac{\left(\bar{R}+\Delta R_{3}\right) \cdot\left(3 \bar{R}+\Delta R_{1}+\Delta R_{2}+\Delta R_{4}\right)}{\sum R} \\
& R_{c d}=\frac{\left(\bar{R}+\Delta R_{4}\right) \cdot\left(3 \bar{R}+\Delta R_{1}+\Delta R_{2}+\Delta R_{3}\right)}{\sum R} \\
& R_{d b}=\frac{\left(2 \bar{R}+\Delta R_{1}+\Delta R_{2}\right) \cdot\left(2 \bar{R}+\Delta R_{3}+\Delta R_{4}\right)}{\sum R} \\
& R_{d b}=\frac{\left(2 \bar{R}+\Delta R_{1}+\Delta R_{4}\right) \cdot\left(2 \bar{R}+\Delta R_{2}+\Delta R_{3}\right)}{\sum R}
\end{aligned}
$$

with

$$
\sum R=4 \bar{R}+\Delta R_{1}+\Delta R_{2}+\Delta R_{3}+\Delta R_{4}
$$

From this point onwards one introduces the assumption that the sum of the deviations from the mean resistance is zero:

$$
\Delta R=\Delta R_{1}+\Delta R_{2}+\Delta R_{3}+\Delta R_{4}=0
$$

Inserting this into the first equation of A. 4 yields

$$
\begin{gathered}
R_{a d}=\frac{1}{4 \bar{R}}\left(3 \bar{R}^{2}+\bar{R} \Delta R_{2}+\bar{R} \Delta R_{3}+\bar{R} \Delta R_{4}+3 \bar{R} \Delta R_{1}\right. \\
\left.+\Delta R_{1} \Delta R_{2}+\Delta R_{1} \Delta R_{3}+\Delta R_{1} \Delta R_{4}\right) .
\end{gathered}
$$

Applying the same to all equations of A.4 and neglecting the quadratic terms of the deviations the whole set of equations now reads:

$$
\begin{aligned}
& R_{a d}=\frac{1}{4}\left(3 \bar{R}+3 \Delta R_{1}+\Delta R_{2}+\Delta R_{3}+\Delta R_{4}\right) \\
& R_{a b}=\frac{1}{4}\left(3 \bar{R}+\Delta R_{1}+3 \Delta R_{2}+\Delta R_{3}+\Delta R_{4}\right) \\
& R_{b c}=\frac{1}{4}\left(3 \bar{R}+\Delta R_{1}+\Delta R_{2}+3 \Delta R_{3}+\Delta R_{4}\right) \\
& R_{c d}=\frac{1}{4}\left(3 \bar{R}+\Delta R_{1}+\Delta R_{2}+\Delta R_{3}+3 \Delta R_{4}\right) \\
& R_{d b}=\bar{R}+\frac{1}{2}\left(\Delta R_{1}+\Delta R_{2}+\Delta R_{3}+\Delta R_{4}\right) \\
& R_{a c}=\bar{R}+\frac{1}{2}\left(\Delta R_{1}+\Delta R_{2}+\Delta R_{3}+\Delta R_{4}\right)
\end{aligned}
$$

Together with equation A.6 this builds up a set of equations which can be solved. To do so, the vector of results $\vec{x}$ can be related to the vector of measurements $\vec{b}$ using the matrix $M$ according to

$$
\vec{x}=\left(M^{T} M\right)^{-1} \cdot M^{T} \vec{b}
$$

with

$$
\begin{aligned}
& \vec{x}=\left(\begin{array}{c}
\bar{R} \\
\Delta R_{1} \\
\Delta R_{2} \\
\Delta R_{3} \\
\Delta R_{4}
\end{array}\right) \\
& \vec{b}=\left(\begin{array}{c}
R_{a d} \\
R_{a b} \\
R_{b c} \\
R_{c d} \\
R_{d b} \\
R_{a c} \\
\Delta R
\end{array}\right) \\
& M=\left(\begin{array}{ccccc}
\frac{3}{4} & \frac{3}{4} & \frac{1}{4} & \frac{1}{4} & \frac{1}{4} \\
\frac{3}{4} & \frac{1}{4} & \frac{3}{4} & \frac{1}{4} & \frac{1}{4} \\
\frac{3}{4} & \frac{1}{4} & \frac{1}{4} & \frac{3}{4} & \frac{1}{4} \\
\frac{3}{4} & \frac{1}{4} & \frac{1}{4} & \frac{1}{4} & \frac{3}{4} \\
1 & \frac{1}{2} & \frac{1}{2} & \frac{1}{2} & \frac{1}{2} \\
1 & \frac{1}{2} & \frac{1}{2} & \frac{1}{2} & \frac{1}{2} \\
0 & 1 & 1 & 1 & 1
\end{array}\right)
\end{aligned}
$$

Finally, one gets the result for all individual resistances:

$$
\begin{aligned}
\bar{R} & =\frac{3}{17}\left(R_{a b}+R_{b c}+R_{c d}+R_{d a}\right)+\frac{4}{17}\left(R_{a c}+R_{d b}\right) \\
R_{1} & =\bar{R}+\frac{1}{2}\left(-R_{a b}-R_{b c}-R_{c d}+3 R_{d a}\right) \\
R_{2} & =\bar{R}+\frac{1}{2}\left(3 R_{a b}-R_{b c}-R_{c d}-R_{d a}\right) \\
R_{3} & =\bar{R}+\frac{1}{2}\left(-R_{a b}+3 R_{b c}-R_{c d}-R_{d a}\right) \\
R_{4} & =\bar{R}+\frac{1}{2}\left(-R_{a b}-R_{b c}+3 R_{c d}-R_{d a}\right)
\end{aligned}
$$

The above set of equations has proven to be a good approximation to the real values in case the manufacturing tolerances indeed result in small deviations of individual resistances from the mean value so that equation A.6 is valid. This is of course not any more the case if the meander should be damaged $(R=\infty)$ or have a shortcut $(R \ll \bar{R})$. Corresponding measurement results will be obvious and easily identifiable.

As channel 3 has the same track layout, the same set of equations applies. For the channels 1 and 4 with their slightly different track layout (compare Figure A.10) simple permutation of the indices according to the location of meander resistors in relation to the contact pads 
yields:

$$
\begin{aligned}
\bar{R} & =\frac{3}{17}\left(R_{a b}+R_{b c}+R_{c d}+R_{d a}\right)+\frac{4}{17}\left(R_{a c}+R_{d b}\right) \\
R_{1} & =\bar{R}+\frac{1}{2}\left(3 R_{a b}-R_{b c}-R_{c d}-R_{d a}\right) \\
R_{2} & =\bar{R}+\frac{1}{2}\left(-R_{a b}+3 R_{b c}-R_{c d}-R_{d a}\right) \\
R_{3} & =\bar{R}+\frac{1}{2}\left(-R_{a b}-R_{b c}+3 R_{c d}-R_{d a}\right) \\
R_{4} & =\bar{R}+\frac{1}{2}\left(-R_{a b}-R_{b c}-R_{c d}+3 R_{d a}\right)
\end{aligned}
$$

\section{Data availability}

The raw/processed data required to reproduce these findings cannot be shared at this time due to technical or time limitations.

\section{References}

[1] G. Vayakis, E. R. Hodgson, V. Voitsenya, C. I. Walker, Generic diagnostic issues for a burning plasma experiment, in: A. E. Costley, D. W. Johnson (Eds.), Special issue on plasma diagnostics for magnetic fusion research, volume 53, Fusion Science and Technology, 2008.

[2] A. Suarez, R. Reichle, M. Loughlin, E. Polunovskiy, M. Walsh, Neutronic analysis for bolometers in \{ITER\}, Fusion Engineering and Design 88 (2013) 1395-1399. Proceedings of the 27th Symposium On Fusion Technology (SOFT-27); Liège, Belgium, September 24-28, 2012.

[3] K. F. Mast, J. C. Vallet, C. Andelfinger, P. Betzler, H. Kraus, G. Schramm, A low noise highly integrated bolometer array for absolute measurement of VUV and soft-X radiation, Review of Scientific Instruments 62 (1991) 744-750.

[4] T. Nishitani, T. Shikama, R. Reichle, E. R. Hodgson, E. Ishitsuka, S. Kasai, S. Yamamoto, In-situ irradiation test of mica substrate bolometer at the JMTR reactor for the ITER diagnostics, Fusion Engineering and Design 63-64 (2002) 437-441.

[5] M. Gonzalez, E. R. Hodgson, Radiation resistant alternative substrates for ITER bolometers, Fusion Engineering and Design 66-68 (2003) 881-885.

[6] M. Gonzalez, E. R. Hodgson, Radiation resistant bolometers using platinum on $\mathrm{Al} 2 \mathrm{O} 3$ and AlN, Fusion Engineering and Design 74 (2005) 875-878.

[7] M. Gonzalez, E. Hodgson, Radiation resistant bolometers with al2o3 and aln substrates, anodized aluminium support frames, and improved electrical contacts, Fusion Engineering and Design 84 (2009) 829 - 831. Proceeding of the 25th Symposium on Fusion Technology - (SOFT-25).

[8] A. Gusarov, S. Huysmans, L. Vermeeren, E. R. Hodgson, M. Decreton, In situ in-reactor testing of potential bolometer materials for ITER plasma diagnostics, Fusion Engineering and Design 82 (2007) 1179-1184. 24th Symposium on Fusion Technology (SOFT-24), Warsaw, POLAND, SEP 11-15, 2006.

[9] L. Giannone, D. Queen, F. Hellman, J. C. Fuchs, Prototype of a radiation hard resistive bolometer for ITER, Plasma Physics and Controlled Fusion 47 (2005) 2123-2143.
[10] H. Meister, T. Eich, N. Endstrasser, L. Giannone, M. Kannamüller, A. Kling, J. Koll, T. Trautmann, P. Detemple, S. Schmitt, Optimization of a bolometer detector for ITER based on Pt absorber on SiN membrane, Review of Scientific Instruments 81 (2010) 10E132.

[11] H. Meister, M. Kannamüller, J. Koll, A. Pathak, F. Penzel, T. Trautmann, P. Detemple, S. Schmitt, H. Langer, Reliability issues for a bolometer detector for ITER at high operating temperatures, Review of Scientific Instruments 83 (2012) 10 D724.

[12] A. Gusarov, S. Huysmans, L. Giannone, H. Meister, Radiation stability of resistive bolometers intended for operation in the ITER environment, Fusion Engineering and Design 86 (2011) 1200-1203. 26th Symposium on Fusion Technology (SOFT), Porto, PORTUGAL, SEP 27-OCT 01, 2010.

[13] H. Meister, H. Langer, S. Schmitt, An alternative geometry for bolometer sensors for use at high operating temperatures, Fusion Engineering and Design 112 (2016) 579-586.

[14] H. Meister, M. Bernert, W. Biel, M. Han, L. Ingesson, K. Mukai, F. Penzel, B. Peterson, R. Reichle, M. Reinke, S. Schmitt, D. Zhang, Bolometer developments in diagnostics for magnetic confinement fusion, Journal of Instrumentation 14 (2019) C10004-C10004.

[15] A. Hogenbirk, An easy way to perform a radiation damage calculation in a complicated geometry, Fusion Engineering and Design 83 (2008) 1828 - 1831. Proceedings of the Eight International Symposium of Fusion Nuclear Technology.

[16] S. Zinkle, L. Snead, Influence of irradiation spectrum and implanted ions on the amorphization of ceramics, Nuclear Instruments and Methods in Physics Research Section B: Beam Interactions with Materials and Atoms 116 (1996) 92 - 101. Radiation Effects in Insulators. 